\title{
A simple method for estimating flood discharge in gravel-bed channels with varied riverbed level
}

\author{
J.-H. Hong, W.-D. Guo \& H.-W. Wang \\ Taiwan Typhoon and Flood Institute, National Applied Research Laboratories, Taiwan \\ P.-H. Yeh \\ Department of Marine Environment and Engineering, National Sun Yat-sen University, Taiwan
}

\begin{abstract}
The information of flow discharge in channels is crucial for river planning and regulation, weir and reservoir operation, river crossing and encroachment remediation, and river restoration. It also affects the degree of erosion on the channel bed and river bank, and scour around structures in the riverine environment. During a flood event, large scour on the channel bed and rapid sediment transport along the channel reach occur at the flood rising stages. Significant changes of riverbed level appear consequently. However, the conventional method of on-site measurements is time-consuming and dangerous for the investigators. A simple method utilizing non-contact water-surface velocity radar (SVR) and ground-penetrating radar (GPR) was developed. Two rating curves, the relationships for the stream mean velocity and river cross section to the stream surface velocity, were investigated. The resultant stream discharge shows great improvement of the estimation of entire flood hydrograph, indicating that the proposed method has the capability to reasonably estimate the flood discharges of gravel channels with mobile bed.
\end{abstract}

\section{GENERAL INSTRUCTIONS}

Real-time measurements of flow velocity and stream cross section are essential for the estimation of flow discharge in a river. A sounding weight with a propeller-type current meter are commonly used to measure water depth and channel velocity, respectively. Acoustic Doppler velocity profilers (ADVPs) installed on a moving boat is getting popular and widely used to measure flow discharge for it greatly reduces the operation time. However, extreme flow conditions which occur more frequently due to global climate change cause drastic changes of stream cross section during high flow. It is then difficult for hydrologists to measure flow velocities and cross section profiles during an entire flood event. Therefore, a specific stage-discharge relationship needs to be established for continuous recording of flow discharge in a stream gauging station. However, as Rantz (1982) pointed out, with variable backwater effect or under unsteady flow conditions, the singleparameterized rating curve hardly defines the varied discharge that would occur in the stream. In addition, if the riverbed level changes significantly during flood events, the stage-discharge relationship may not be adequately applicable either.

In unstable channels with steep-channel slope, such as gravel-bed rivers, gauging during a flood event is dangerous because of the high flow velocities and drifters-logs, stumps and debris. Moreo- ver, depth-measuring equipment is increasingly subject to errors and/or failures as stream depth, velocity, and bed instability increase (Sauer and Meyer, 1992). Several non-contact methods have been developed to measure the stream cross section. Spicer et al. (1997) used a ground-penetrating radar (GPR, GSSI system-10) with $60-300 \mathrm{MHz}$ antennas suspending above the river. Alternatively, a Mala Geoscience Ramac X3M Corder GPR system which used shield antennas with a central frequency of 100 $\mathrm{MHz}$ weighting around $25-30 \mathrm{~kg}$ and suspending $0.5-2 \mathrm{~m}$ above the water surface on a light cableway system was used by Costa et al. (2006). Since the GPR return signals were very complex, interpretation of the signals was difficult. Most of the GPR data interpreted by experts with special training or knowledge were less objective. Furthermore, no algorithm was provided in Spicer et al. (1997) or Costa et al. (2006) to distinguish between the air-water and water-riverbed interfaces. In order to reduce the subjective judgement on the GPR images, Chen et al. (2014) employed Hilbert-Huang transform (HHT) to post-process the GPR signals. Overall, GPR is a technology for mapping stream cross-sectional profile at high flow, particularly under conditions when conventional methods are either unsafe or inadequate. Additionally, stream cross-sectional profiles with finer resolution are obtained for better realizations of the cross section shape than those by using conventional point measurements with sounding 
weights. Riverbed geometry then can be determined reasonably by GPR, especially if the channel undergoes significant general scour during floods.

Determining channel mean velocity for the stream discharge is another difficult task for the hydrologists. Recently, the application of the index-velocity method has become increasingly common (Oberg and Levesque, 2012). The method differs from the stage-discharge method by separating stream velocity and flow area into two separate ratings - an indexvelocity rating and a stage-area rating. The channel cross-sectional mean velocity might be a function of channel streamwise velocity, water stage, channel slope, or bed roughness. On the other hand, the flow area might be a function of water stage or channel cross-sectional shape. However, the index-velocity method is still rarely used for unstable channels, especially for a river reach with significant riverbed level or cross section change during flood events.

The objective of this study is to develop a simple method for real-time estimation of flow discharge in a gravel-bed channel. A combination of groundpenetrating radar (GPR) and water surface-velocity radar (SVR) provides a non-contact measuring technology. The GPR along with a water gauge are used to obtain the stream cross-sectional profile and flow area. On the other hand, the SVR is used to measure the flow surface velocity. Field data collected during flood events are employed to establish rating curves for a modified index method. Comparisons are made to evaluate the accuracies of the method relative to the stage-discharge rating.

\section{SITE DESCRIPTION}

Fig. 1 shows the map of the Cho-Shui River basin, which is the longest river in Taiwan. The Mingchu Bridge locates in the middle reach of the river with upstream catchment area of about $2,105 \mathrm{~km}^{2} .6 .5 \mathrm{~km}$ upstream from the bridge, there exists the Chichi weir. Since there's no tributary between the weir and the bridge, the stream discharge released from the weir is fairly close to the flow rate at the latter. The on-site measurements of the river cross-sectional profile, flow velocity and water stage were then conducted at the bridge, with the flow rate information collected from the weir. In addition, there's no scour countermeasure found near the bridge foundation. The historical record for the longitudinal riverbed profile downstream from the weir is shown in Fig. 2. An approximate $6.5 \mathrm{~m}$ degradation of the mean bed level can be seen from 2001 to 2011, which indicates substantial bed degradation near the Mingchu Bridge. This implies that the stream cross-section profile may change significantly during flood events.

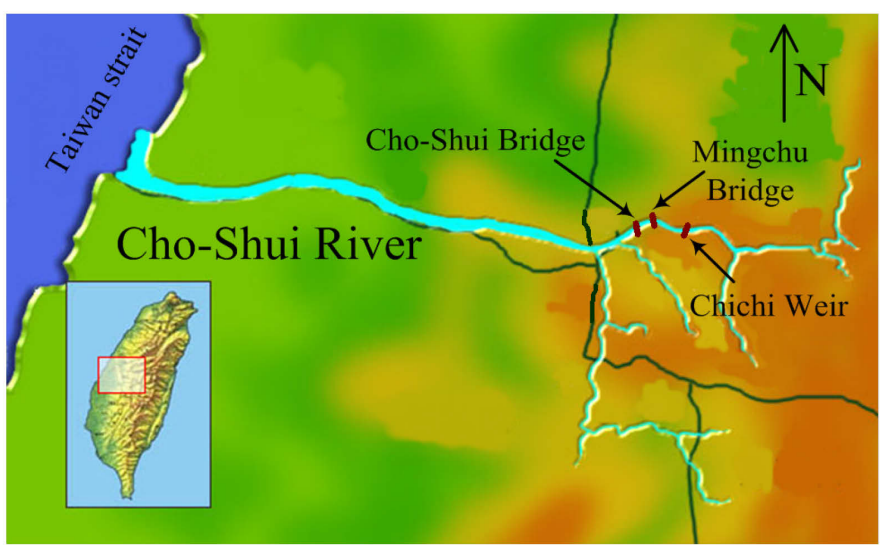

Figure 1. Map of the Cho-Shui river basin.

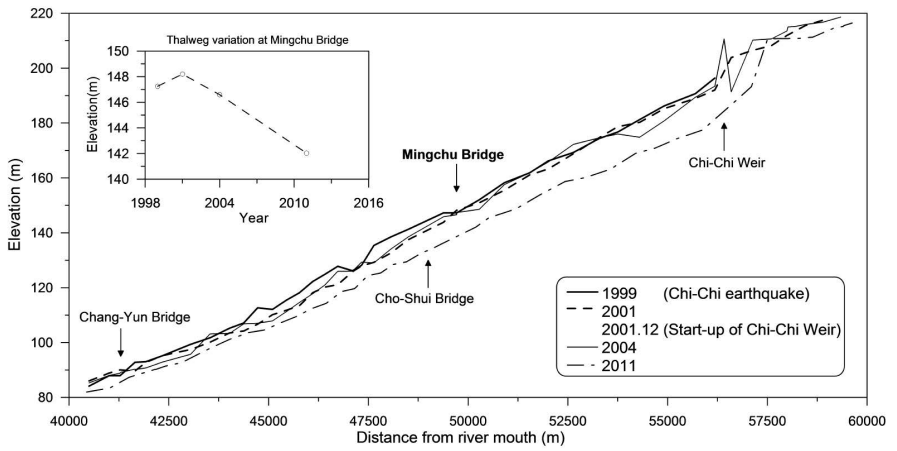

Figure 2. Longitudinal riverbed profile of the Cho-Shui River near the Mingchu Bridge.

\section{FIELD MEASUREMENTS OF STREAM CROSS SECTIONS}

\subsection{Measurement setup}

As shown in the aero photo of the Cho-Shui River (Fig. 3) which was taken after the Typhoon Saola (September, 2012), the Shuidiliaw Embankment downstream of the Mingchu Bridge was apparently broken by the torrential flow induced by the typhoon. The flow path, as a result, shifted and included the Piers 3 and 4 in the main channel. A water surface-velocity radar (SVR) and a water-gauge radar were both installed on the upstream desk of the bridge, to continuously record the water-surface velocity and water stage (Fig. 4a). At the same time, a ground-penetrating radar (GPR) system, which was a Mala system and composited of shielded antennas was used to measure the riverbed cross section. A crane was attached to a truck and lowered the GPR antenna to a height $0.5-1.0 \mathrm{~m}$ above the water surface. Figs. 4(b) and 4(c) show the installation of the GPR system and the measuring water depth along the side of the bridge. 


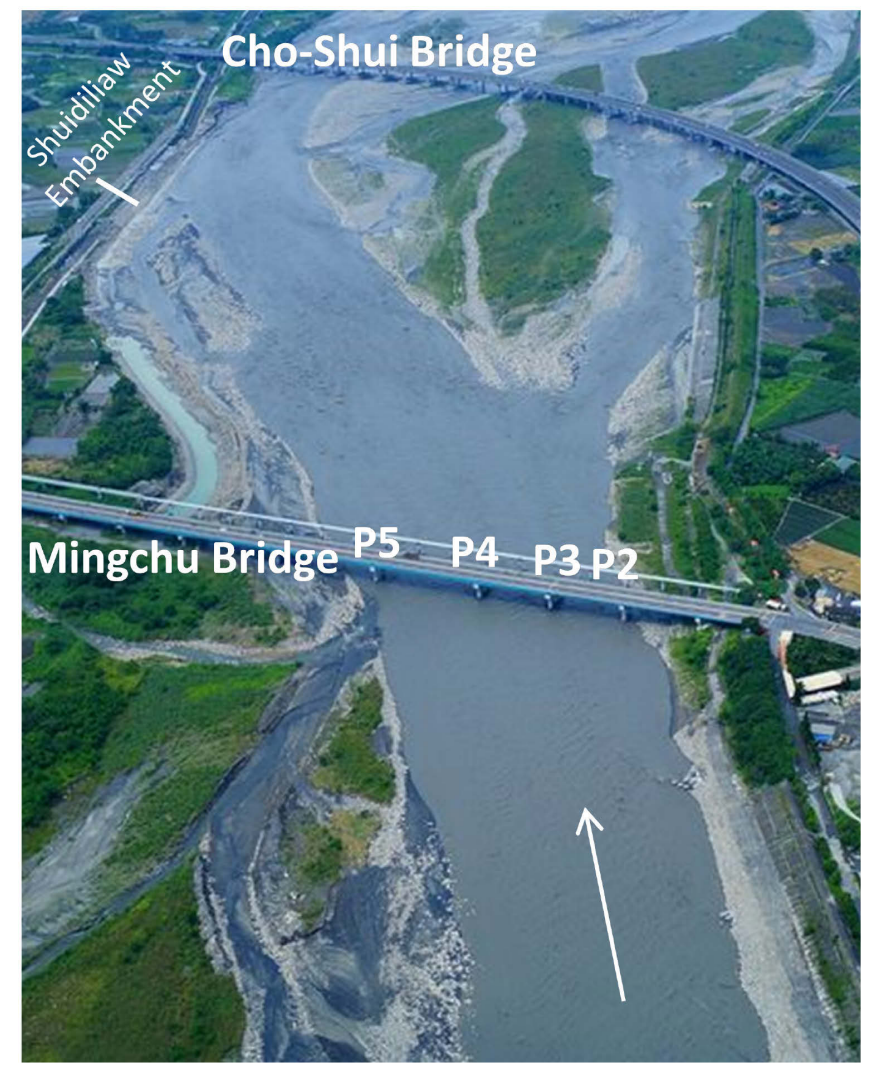

Figure 3. Aero photo of the Cho-Shui River at the Mingchu Bridge.

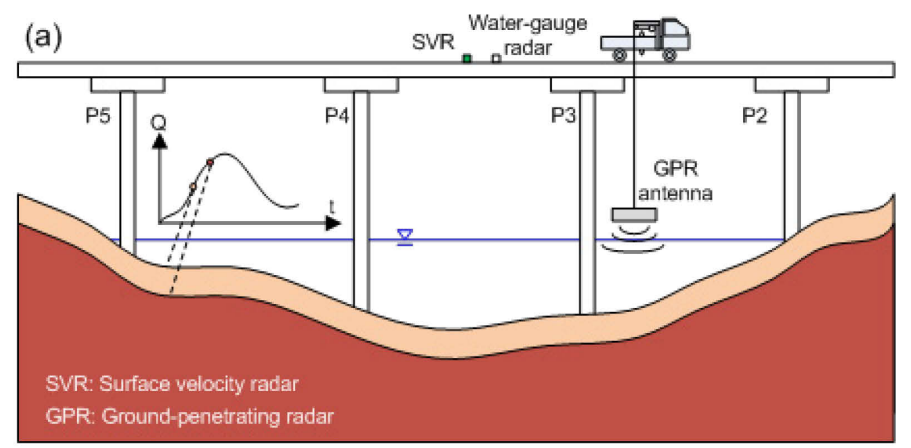

(b)

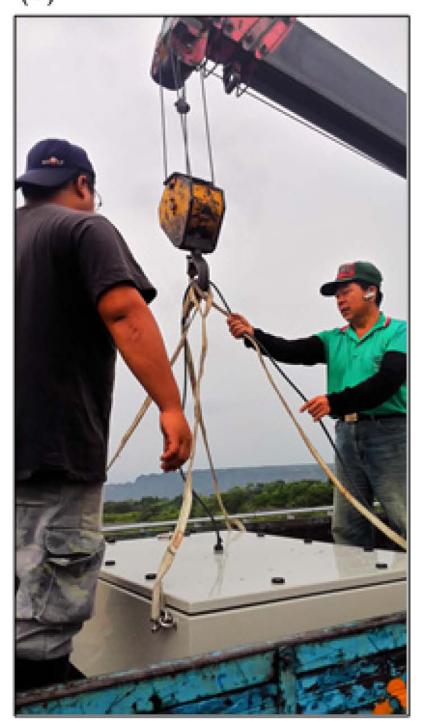

(c)

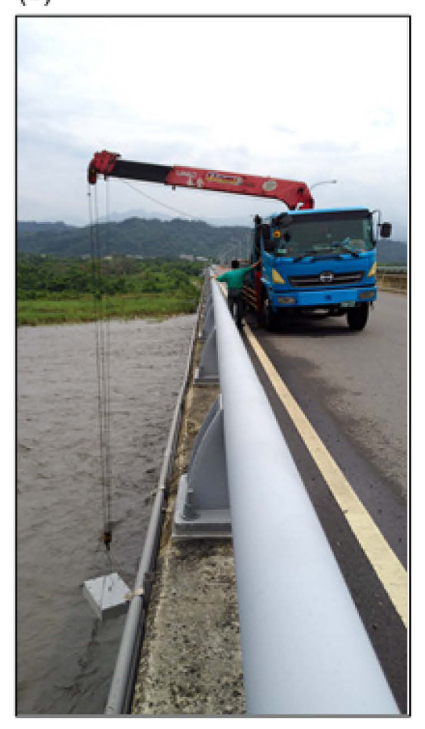

Figure 4. (a) Schematic diagram of the GPR system to measure the stream cross section; (b) installation of the system; (c) measuring water depth along the side of the bridge.

\subsection{Using GPR to measure water depth}

The basic idea of using the GPR system to determine the air-water and water-riverbed interfaces can be illustrated in Fig. 5. When the antennas of the GPR system transmit electro-magnetic waves through air and water bodies, the wave signals are reflected back after they reach the riverbed. As the transmitted mediums change, i.e. from air, water and to riverbed, the amplitudes of the receiving signals become scattering. Considerable noises are also contained in the signals due to the unevenness and non-uniformness of the natural river. DC-filter and Automatic gain control (AGC) are then applied to remove the noises and enhance the output image (Sandmeier, 2012). Fig. 6 shows the resultant GPR output image after filtering the noises. The dark area in the top of the image demonstrates the air-water interface, while the pattern of plaits in the bottom indicates that the riverbed material is gravel. In between, a grey band is suspected to be the real riverbed when performing the GPR measuring. Note that the two parabolic curves in the image indicate the receiving electromagnetic signals are affected by the pier foundations of the Mingchu Bridge.

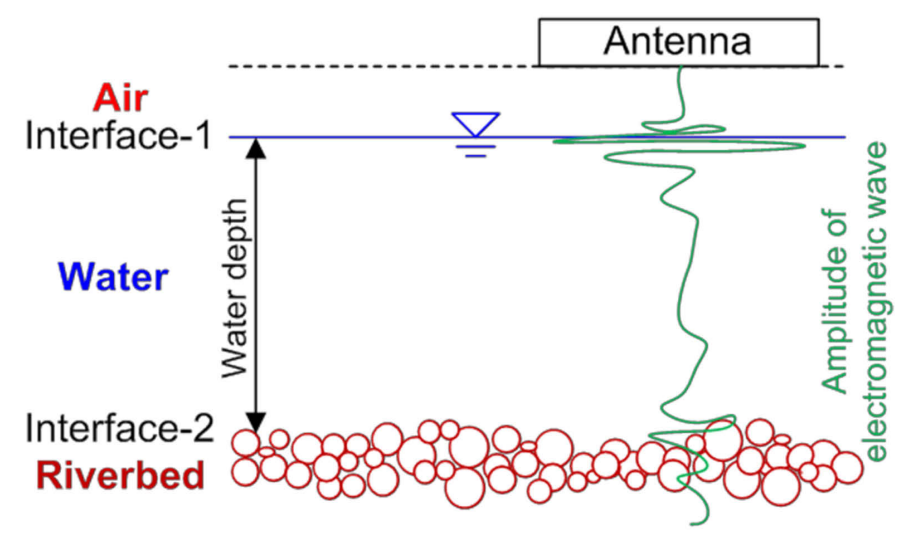

Figure 5. Using GPR to measure the flow depth.

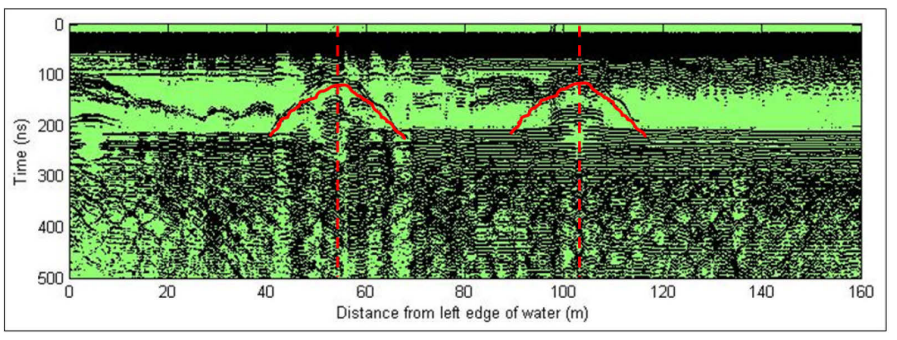

Figure 6. GPR image output.

\subsection{Post-processing of the GPR data (Chen, 2014)}

After identifying the air-water and water-riverbed interfaces, the GPR image is converted into the river cross-sectional profile; water depth is obtained after multiplying the signal traveling time with the speed of the electro-magnetic wave in water $(\approx 0.033$ $\mathrm{m} / \mathrm{ns})$. Fig. 7 shows the conversion of the image without removing spikes. The air-water interface is 
smooth while apparent spikes exist in the waterriverbed interface, resulting in difficult determination of the interface. After removing the spikes and smoothing the curve, the final output in Fig. 8 demonstrates an identifiable river cross-sectional profile.

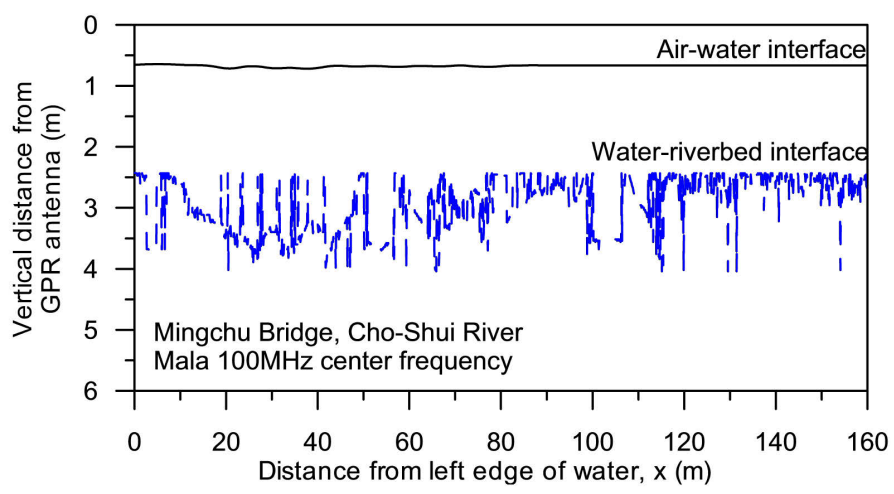

Figure 7. Conversion of GPR image without removing noises.

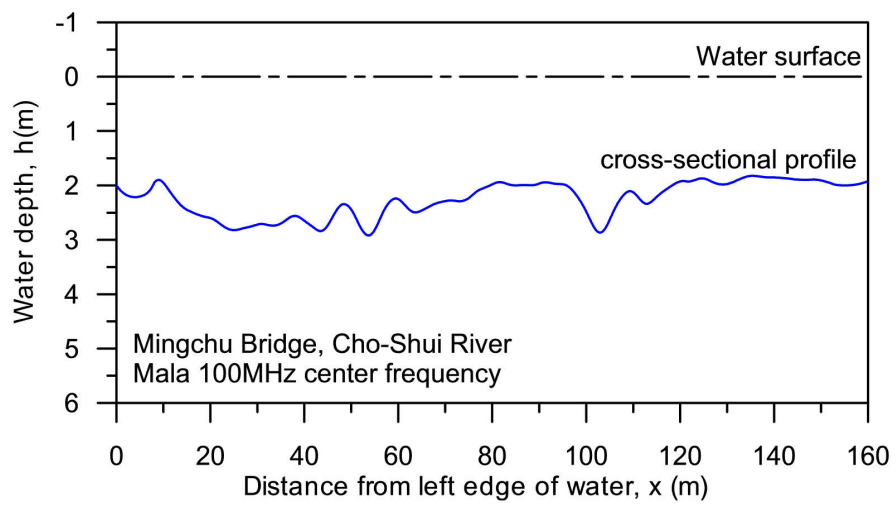

Figure 8. River cross-sectional profile after post-processing.

\section{RESULTS AND DISCUSSIONS}

Table 1 lists the on-site flow conditions for the GPR measurements. Eleven tests in six flood events were conducted between May 2014 and Aug. 2015. Two different central frequencies of GPR antenna, $100 \mathrm{MHz}$ and $250 \mathrm{MHz}$, were used. Flow condition changed dramatically from low flow with sand bar to high flow. Stream discharge also varied from 6.7 to $1,473 \mathrm{~m}^{3} / \mathrm{s}$.
Table 1. Flow conditions at the Mingchu Bridge

\begin{tabular}{|c|c|c|c|c|}
\hline Date & $\begin{array}{l}\text { Flood } \\
\text { events }\end{array}$ & $\begin{array}{c}\text { Antenna } \\
\text { frequency } \\
(\mathrm{MHz})\end{array}$ & $\begin{array}{c}\text { Discharges } \\
\text { during GPR } \\
\text { measurements } \\
\left(\mathrm{m}^{3} / \mathrm{s}\right)\end{array}$ & Remarks \\
\hline $5 / 29 / 2014$ & Monsoon & 100 & 66.82 & $\begin{array}{c}\text { Low to medi- } \\
\text { um flow }\end{array}$ \\
\hline $7 / 24 / 2014$ & $\begin{array}{l}\text { Typhoon } \\
\text { Matmo }\end{array}$ & 100 & $\begin{array}{c}1348,1390 \\
1473\end{array}$ & High flow \\
\hline $9 / 22 / 2014$ & $\begin{array}{c}\text { Typhoon } \\
\text { Fong-wong }\end{array}$ & 250 & 11.38 & $\begin{array}{l}\text { Low flow } \\
\text { with sand bar }\end{array}$ \\
\hline $7 / 12 / 2015$ & $\begin{array}{c}\text { Typhoon } \\
\text { Chon-Hom }\end{array}$ & 250 & 6.70 & $\begin{array}{c}\text { Low flow } \\
\text { with sand bar }\end{array}$ \\
\hline $8 / 9 / 2015$ & $\begin{array}{l}\text { Typhoon } \\
\text { Soudelor }\end{array}$ & 250 & $\begin{array}{l}351,363, \\
385,452\end{array}$ & Medium flow \\
\hline $8 / 23 / 2015$ & $\begin{array}{c}\text { Typhoon } \\
\text { Goni }\end{array}$ & 250 & 10.58 & $\begin{array}{c}\text { Low flow } \\
\text { with sand bar }\end{array}$ \\
\hline
\end{tabular}

\subsection{River cross-sectional profiles}

In order to evaluate the consistency of this noncontact technology and the methodology of this study, the river cross-sectional profile obtained from the GPR system was compared to the measurements by using sounding weight. Figure 9 illustrates the river cross-sectional profiles at the Mingchu Bridge during four different typhoons. The horizontal and vertical axes are the distance from the left bank reference and the corresponding water depth, respectively. The results show that the GPR data are consistent to the measurements by using sounding weight. Discrepancies increase at the areas near the pier foundations. Nonetheless, the GPR system has the advantage of providing higher spatial resolution for the channel cross-sectional profile.

Figure 10 plots the GPR results for the crosssectional profiles at the Mingchu Bridge under different flood events. It clearly shows that the top width of the cross section increases with the discharge. The riverbed level also lowers as the river flowrate increases. This may infer that the channel cross-sectional geometry changes significantly along with flow discharge. Intensive sediment transport takes place in the river reach, especially under high flow conditions. As Herschy (2009) mentioned, the movement of fluvial sediment, particularly in channels in alluvium, affects the channel conveyance, hydraulic roughness, sinuosity and energy slope, and makes the determination of stage-discharge relationship in such type of river difficult. Moreover, since sediment movement is random and erratic, the temporal variation of stage-discharge relationship is also complex. 

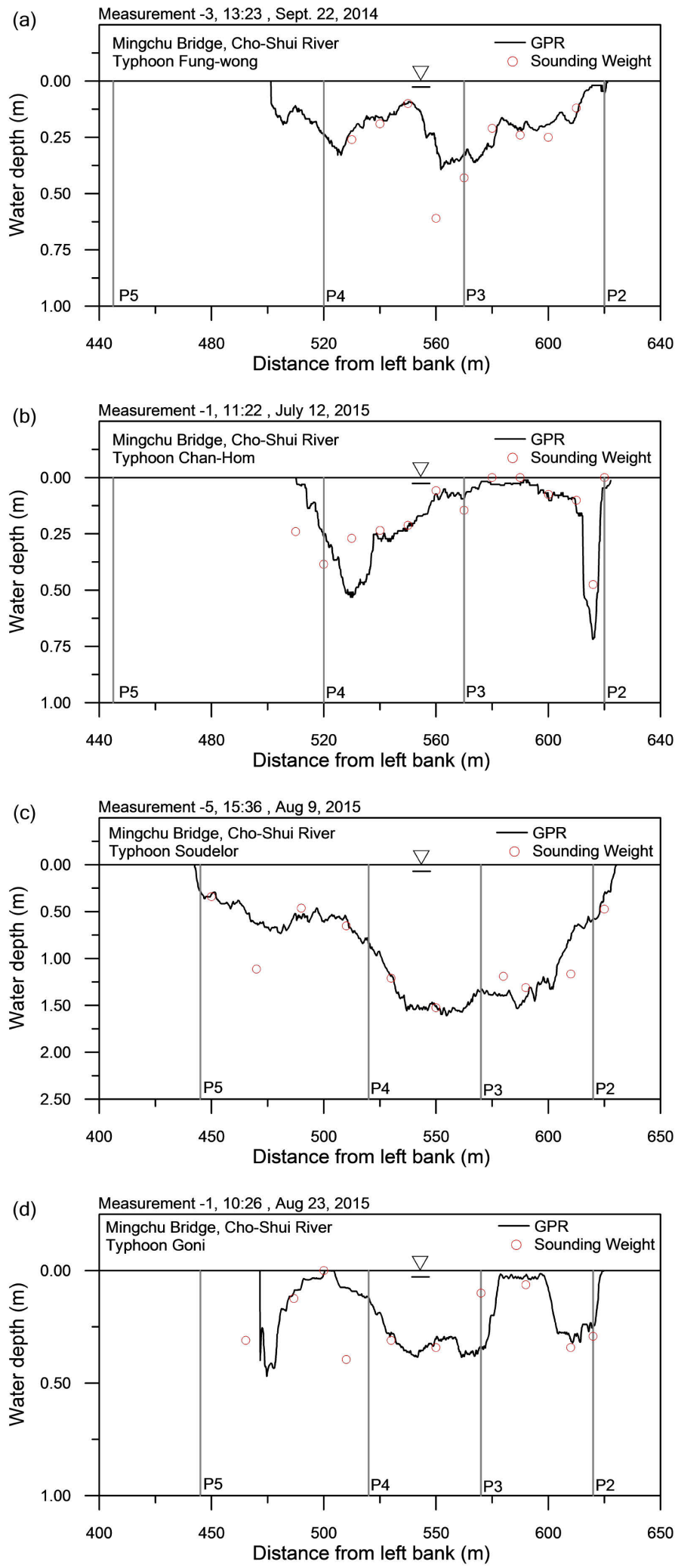

Figure 9. Riverbed cross-sectional profiles at the Mingchu bridge during: (a) Typhoon Fong-wong (Sep 2014); (b) Typhoon Chan-Hom (July 2015); (c) Typhoon Soudelor (Aug 2015); (d) Typhoon Goni (Aug 2015).

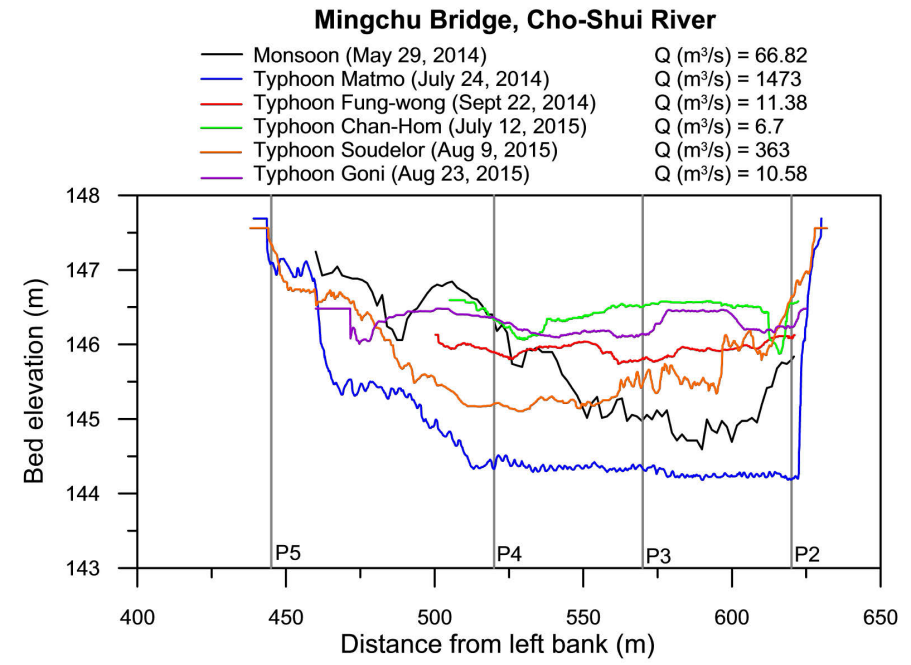

Figure 10. Variations of channel cross section at the Mingchu bridge.

\subsection{Estimation of flow discharge}

Figure 11 lists different methods for the estimation of stream discharge. In general engineering practices, stage-discharge method (Fig. 11a) is most commonly used to determine flow discharge. Recently, the acoustic Doppler velocity meter (ADVM) has also been widely used due to its gradually lower cost. The velocity measurements are collected to develop the so-called index-velocity method, which conducts two rating curves - an index-velocity rating and a stage-area rating - to estimate the discharge (Fig. 11b). The index-velocity rating curve establishes the relationship between the channel cross-sectional mean velocity and a certain measured velocity in the cross section. Huang (2004) used the channel master H-ADCP, and Oberg and Levesque (2012) used ADVM to measure flow velocity for this rating curve. However, both studies installed the equipment in a canal with fixed channel bed and side wall. As mentioned in Fig. 10, the river cross-sectional geometry near the Mingchu Bridge changes significantly during flood events, the obtained stage-area rating might not be adequate. Also, the varied channel bed and high flow conditions near the bridge may damage the equipment installed on the side wall/river bank. As a result, the method of neither Huang (2004) nor Oberg and Levesque (2012) can be directly applicable. Different from the above two methods, the proposed method uses the watersurface velocity radar (SVR), instead of the velocity measured by using ADVM or H-ADCP, for the velocity-area rating and index-velocity rating relationships. It is because the SVR has the advantage of noncontact measurement for the water surface velocity, which cab avoid the instrument damaged by floating drifts. The resulting flow area and channel mean velocity are then multiplied to obtain the stream discharge. The procedure is as in Fig. 11(c). 


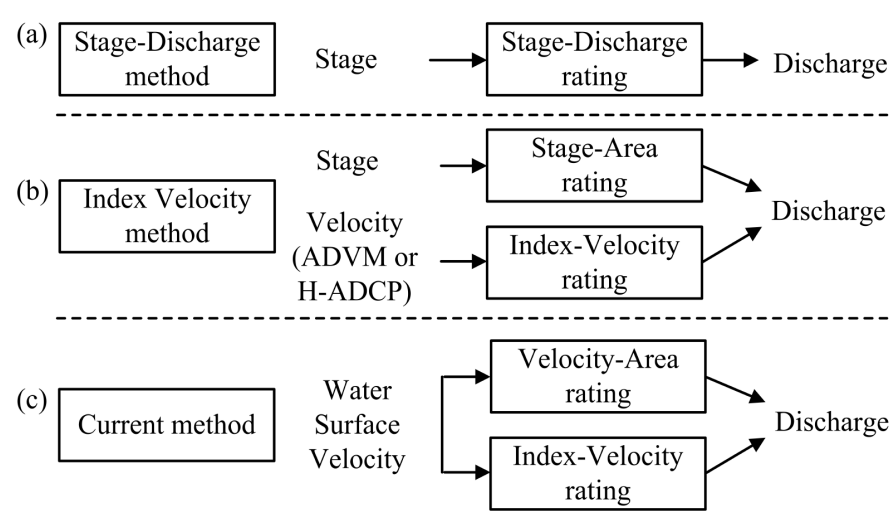

Figure 11. Different methods for the discharge estimation.

Data given in Table 1 are then used to establish all the rating curves for the three methods. Fig. 12 plots the discharge measurements $Q$ against the corresponding water stage $Z$. Two empirical equations are used to evaluate the rating. The dotted line represents a logarithmic curve, which is common in determining the stage-discharge relationship:

$Q=c(Z-a)^{n}$

where $a$ is the water stage at zero flow, and $c$ and $n$ are undetermined coefficients. The regression result shows that the values of $a, c$ and $n$ are 144.302, 0.791 and 5.874, respectively. Another fitting curve with exponential function can be expressed as

$Q=\exp [(\mathrm{Z}-145.928) / 0.252]$

It should be noted that although Eq. (2) provides better regression, $Q$ increases significantly with small increase of $Z$. Large extrapolation error may be created for the estimation of discharge.

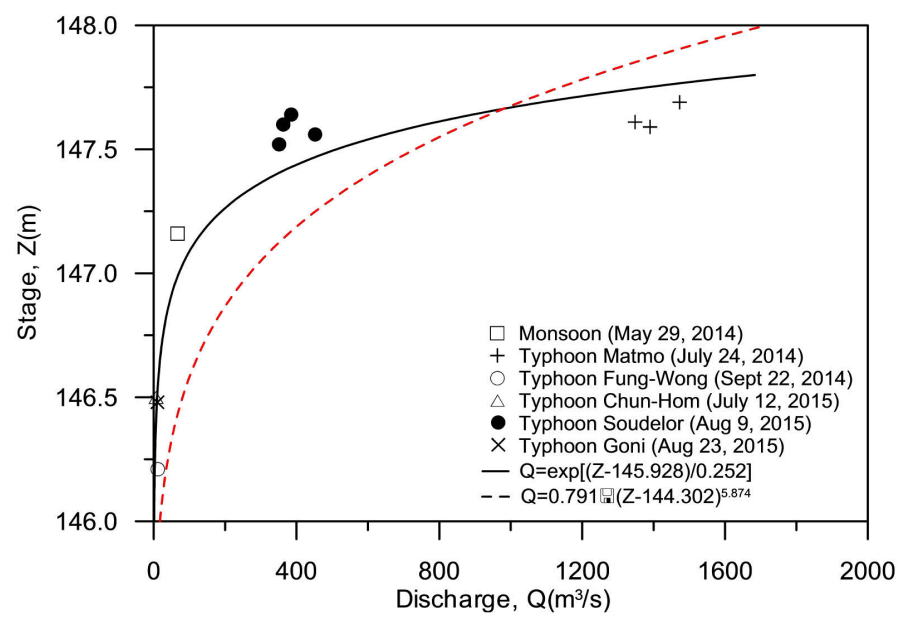

Figure 12. Stream discharge and the corresponding water stage.

The channel cross-sectional mean velocity $U_{m}$ and water surface velocity $U_{w s}$ (index velocity) are plotted in Fig. 13. It can be seen that positive correlation exists between the two velocities. A linear relationship is expressed as
$U_{m}=0.945 U_{w s}-0.548$

Note that Eq. (3) is only valid when $U_{w s}$ is larger than $0.58 \mathrm{~m} / \mathrm{s}$.

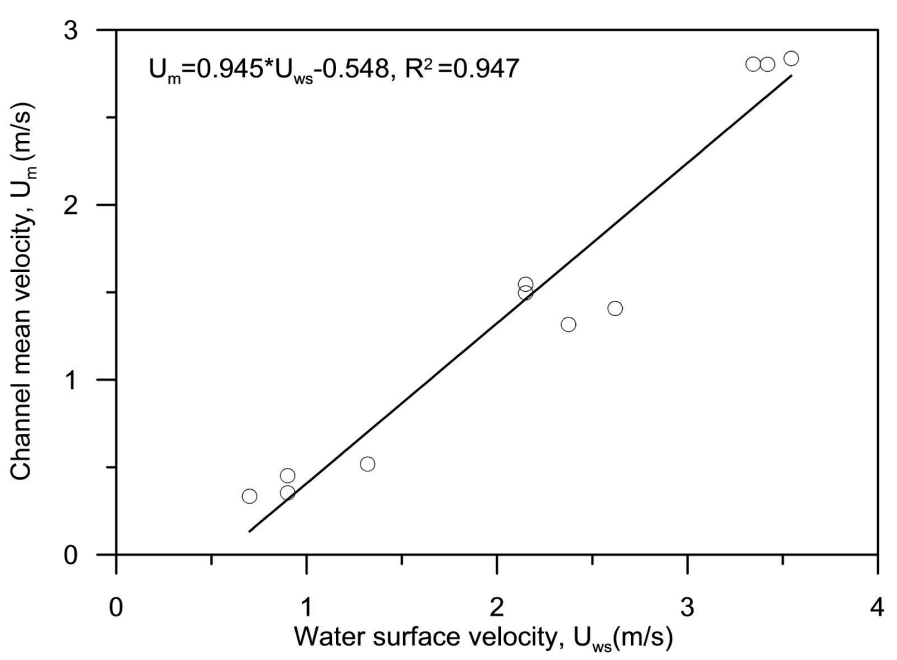

Figure 13. Correlation between water surface and crosssectional mean velocities.

Fig. 14 shows the flow area $A$ and the corresponding water stage $Z$ and water surface velocity $U_{w s}$. It can be seen that $A$ increases rapidly as $Z$ increases. However, since the zero datum changes with flow discharge, a nonlinear relationship exists between these two properties. Additionally, similar to stagedischarge rating curve in Fig. 12, the rapid increase rate of $A$ may over-estimate the flow discharge. On the other hand, $A$ increases linearly with $U_{w s}$ and the data can be well fitted by a straight line. The rating curves of $A$ by using $Z$ and $U_{w s}$ are as

$A=8196027.01-111816.32 Z+381.37 Z^{2}$

$A=178.72 U_{w s}-127.62$

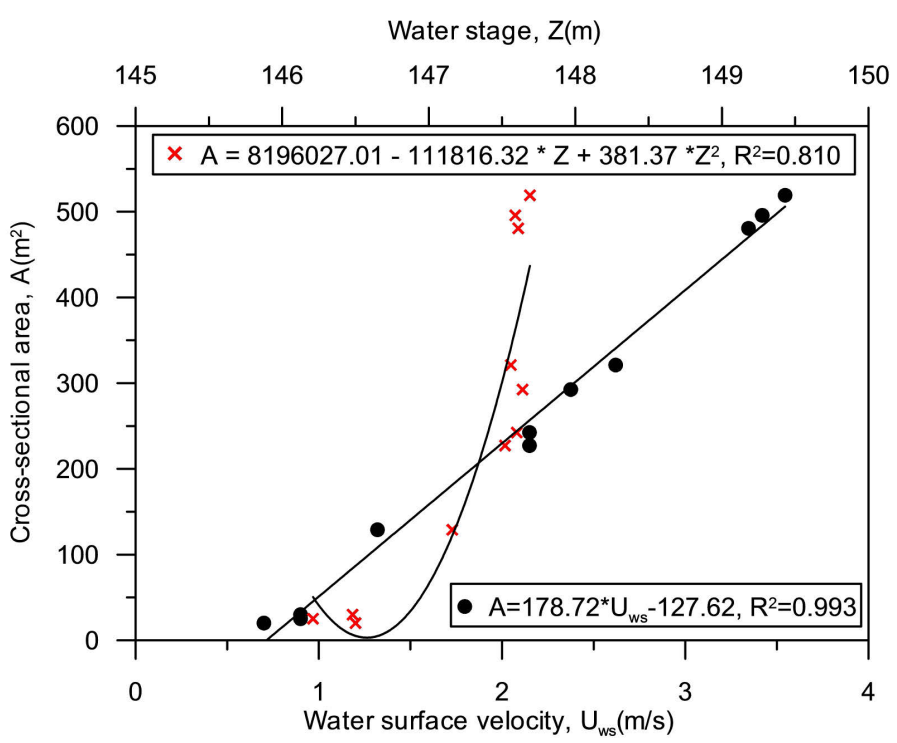

Figure 14. Flow area against water stage and water surface velocity. 


\subsection{Validation of the proposed method}

The flow discharge records from the two flood events induced by Typhoon Kong-Rey (Aug, 2013) and Typhoon Usagi (Sep, 2013) were used for validation and comparison. Fig. 15 plots the stream discharge $Q$ against water stage $Z$ in both events. It should be noted that the inverted (clock-wised) $Z-Q$ loop for both events is different from the common counter clock-wised loop. As mentioned in Figs. 2 \& 10 , significant riverbed degradation and short-term general scour occur in the river reach near the Mingchu Bridge. It explains why the inverted loop appears in the $Z-Q$ curve. Similar results were found in Japan (Fukami et al. 2008).
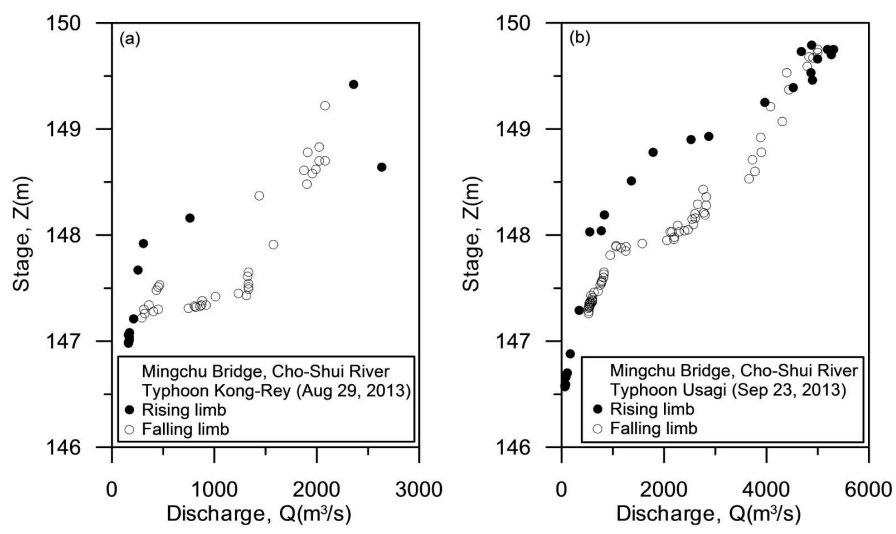

Figure 15. Single-storm stage-discharge loop at the Mingchu Bridge: (a) Typhoon Kong-Rey; (b) Typhoon Usagi.

Figure 16 compares the stream discharge estimated by the conventional stage-discharge method (Eq. 1), index-velocity method (Eqs. $3 \& 4$ ), and the proposed method in this study (Eqs. $3 \& 5$ ). The data used to calibrate the methods ranged from 6.7-1,473 $\mathrm{m}^{3} / \mathrm{s}$. However, the peak discharges for the flood events are 2,633 $\mathrm{m}^{3} / \mathrm{s}$ (Typhoon Kong-Rey) and $5,308 \mathrm{~m}^{3} / \mathrm{s}$ (Typhoon Usagi), which are both much larger than the data range for calibration. As discussed in Figs. $12 \&$ 14, the stream discharge $Q$ and flow area $A$ are sensitive to the water stage $Z$. The result demonstrates over-estimation for $Q$ by both the conventional stage-discharge and index-velocity methods, especially when the stream discharge is high. In contrast, the proposed method gives reasonable prediction values and capable of depicting the entire flood hydrograph very well.
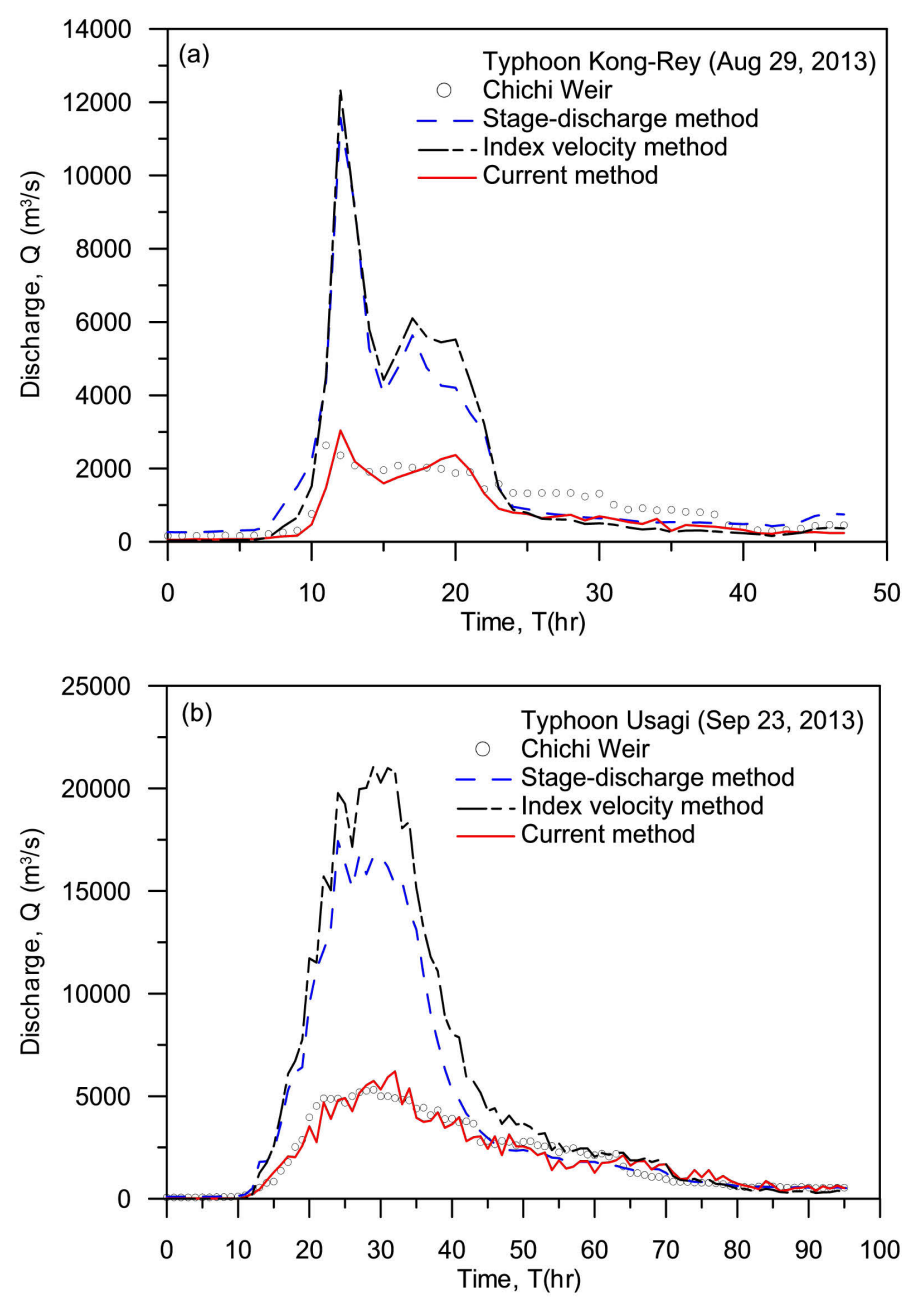

Figure 16. Comparisons of flow discharge for two typhooninduced-flood events: (a) Typhoon Kong-Rey; (b) Typhoon Usagi.

\section{CONCLUSIONS}

The information of riverbed and flow variations were collected near the Mingchu Bridge in the middle of Cho-Shui River, using ground-penetrating radar, water surface radar and water stage meter. Eleven field experiments from 2014-2015 were conducted to develop the proposed method in this study, and to determine the coefficients for the conventional stage-discharge and index velocity methods. Two flood events in 2013 were then used to compare the results to the field measurements. Several findings can be drawn as follows:

1. This study demonstrates that using a track with a crane to carry the GPR antenna suspended above the river surface to map stream cross-sectional profiles is a viable technology. The proposed post-processing method to determine the airwater and water-riverbed interfaces is well consistent with the measurements by using sounding weight. Nonetheless, the accuracy for the area near the pier foundation needs to be improved in the future study.

2. The linear relationships between the mean stream velocity and water surface velocity as 
well as the cross-sectional area are found reasonably accurate, and can be expressed by using Eq. (3) and Eq. (5).

3. Compared to the conventional stage-discharge and index-velocity methods which exhibit overestimation, the proposed method gives closer results to the field measurements. Further study would apply it to different field sites, especially to movable gravel-bed river reaches.

\section{ACKNOWLEDGEMENTS}

The authors would like to thank the Ministry of Science and Technology, Taiwan, for the financial support under Grants number MOST 105WIC7850121.

\section{REFERENCES}

Chen, Y.C., Kao, S.P., and Wu, J.H. (2014). "Measurement of stream cross section using ground penetration radar with Hilbert-Huang transform," Hydrological Processes 28, 2468-2477.

Costa, J.E., Cheng, R.T., Melcher, N., Spicer, K.R., Hayes, E., Plant, W., Hayes, K., Teague, C., Barrick, D. (2006). "Use of radars to minitor stream discharge by noncontact methods." Water Resources Research, 42, W07422, 1-14.

Fukami, K., Yamaguchi, T., and Tashiro, Y. (2008). "Current status of river discharge observation using non-contact current meter for operational use in Japan." World Environmental and Water Resources congress 2008 Ahupua'a.

García, C.M., Tarrab, L., Herrero, H., Oberg, K.A, and Szupiany, R. (2012). "Issues on moving platforms discharge measurements using ADCP on presence of flow fluctuations," Hydraulic Measurements \& Experimental Methods 2012 Conference. Snowbird, UTAH, August 12-15.

Huang, H. (2004). "Index-velocity rating development for rapidly changing flows in an irrigation canal using broadband Stream Pro ADCP and Channel Master H-ADCP." $1^{\text {st }}$ International Conference on Managing Rivers in the $21^{\text {st }}$ Century: Issues \& Challenges, 146-154.

Herschy, R.W. (2009). "Stream Measurement.” 3rd edn, Taylor \& Francis, Abingdon.

Oberg, K.A. and Levesque, V.A. (2012). "Computing discharge using the index velocity method." U.S. Geological Survey Techniques and Methods 3-A23, $148 \mathrm{p}$.

Rantz, S.E., and others. (1982). "Measurement and computation of streamflow-Volume I. Measurement of stage and discharge." U.S. Geology Survey Water-Supply Paper $2175,284 \mathrm{p}$.

Sauer, V.B and Meyer, R.W. (1992). "Determination of error in individual discharge measurements," U.S. Geology Survey Open-File Report 92-144, p.4-7.

Sandmeier Software (2008). ReflexWTM-version 7.0, Karlsruhe, Germany.

Spicer, K.R., Costa, J.E., and Placzek G. (1997). "Measuring flood discharge in unstable stream channels using groundpenetrating radar." Geology, 25(5), 423-426. 